\title{
Quality of home healthcare among Arab countries
}

Malak Al Anazi, HSQM, Khaled Al-Surimi, PhD, MSPH, Amani Abu-Shaheen, MPH.

\begin{abstract}

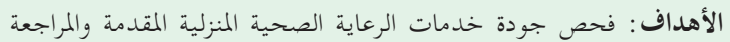

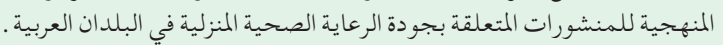

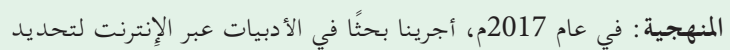

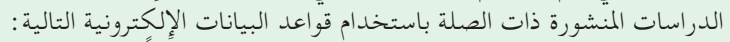

PubMed g CINAHL و Embase

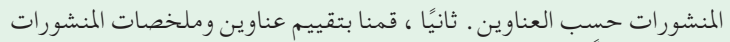

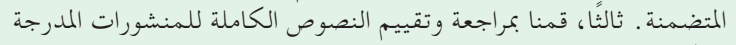

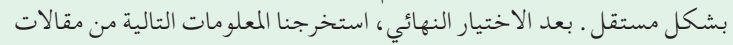

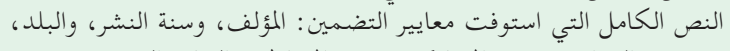

و تصميم الدراسة، وعدد المشار كين، ونوع المشارك ، و النتائج الرئيسية .

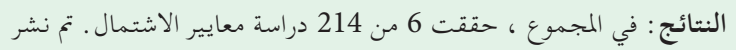

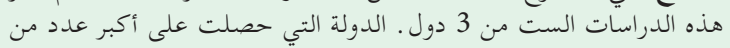

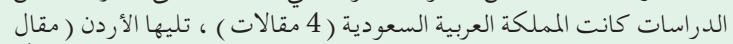

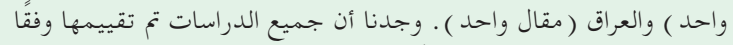

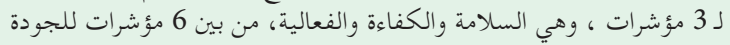
من قبل معهد الطب مئ.

الخلاصة : تُظهر هذه المراجعة فجوة واضحة في الأدبيات المتعلقة بجرودة الرعاية

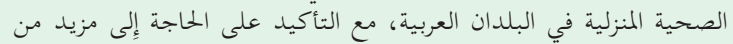

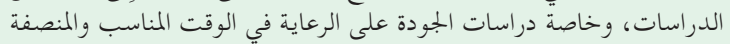
والمتمحورة حول المريض في مجال الرعاية الصحية المنزلية .
\end{abstract}

Objective: To examine the quality of home healthcare services provided and to systematically review publications concerning the quality of home healthcare in Arab countries.

Methods: In 2017, we conducted an online literature search to identify relevant published studies using the following electronic databases: Embase, CINAHL, PubMed, and the Cochrane library. First, we screened the publications according to titles. Second, we evaluated the titles and abstracts of the included publications. Third, we independently reviewed and assessed the full texts of the included publications.

After the final selection, we extracted the following information from the full-text articles that met the inclusion criteria: author, year of publication, country, study design, number of participants, participant type, and the main findings.
Results: In total, 6 of 214 studies met the inclusion criteria. These 6 studies were published from 3 countries. The country with the most number of studies was Saudi Arabia (4 articles), followed by Jordan (one article) and Iraq (one article). We found that all studies were assessed according to 3 indicators, namely, safety, efficiency, and effectiveness, out of the 6 indicators of quality by the Institute of Medicine.

Conclusion: This review shows a clear gap in the literature regarding the quality of home healthcare in Arab countries, emphasizing the need for more studies, particularly quality studies on timely, equitable, and patient-centered care in home healthcare settings.

Keywords: healthcare quality, patient-centered, home health care, Arab countries

Saudi Med J 2020; Vol. 41 (7): 683-689 doi: 10.15537/smj.2020.7.25119

From the Department of Quality Management and Accreditation Office (Al Anazi), from the Research Center (Abu-Shaheen), King Fahad Medical City; and from the from the Department of Health Systems and Quality Management (Al-Surimi), College of Public Health and Health Informatics, King Saud ben Abdulaziz University for Health Sciences Riyadh, Kingdom of Saudi Arabia.

Received 10th September 2019. Accepted 10th April 2020.

Address correspondence and reprint request to: Dr. Malak Al Anazi, Department of Quality Management and Accreditation Office, King Fahad Medical City, Riyadh, Kingdom of Saudi Arabia. E-mail:malanazy@kfmc.med.sa

ORCID ID: https://orcid.org/0000-0002-1019-5548

$\mathrm{Q}$ uality means providing good and useful products to satisfy customer needs and expectations. Quality is defined by the Institute of Medicine (IOM) as having the safe, timely, effective, efficient, equitable, and patient-centered care (STEEP) domains. ${ }^{1}$ Home healthcare (HHC) is the care delivered to patients by expert practitioners in the comfort of their own homes under the directives of a physician. ${ }^{2}$ On the other hand, a home-care setting is far from being an ideal 
environment for delivering healthcare as the hazardous environment of the household acts as a deterrent and increases the chances of nosocomial infections and medication-related errors. ${ }^{3-8}$

Furthermore, healthcare providers can themselves be untrained to deal with the challenges posed and may lack expertise in patient safety. ${ }^{9}$ Therefore, proper supervision, training, and measures for the provision of a safe work environment at home for the healthcare staff are necessary for the success of HHC services.

Combined professional healthcare and life assistance services comprise the home healthcare services (HHCS). ${ }^{2}$ Home healthcare services aims to assist patients in improving their body functions and help them become more independent, to promote patients' level of optimal health, to assist patients in remaining at home, and to avoid hospitalization to long-term care institutes. ${ }^{10-12}$ Welfare states and wealthy countries either directly provide HHCS to patients via nonprofit state agencies or as subsidies via social health insurance or social security programs. For instance, in the United States, the Centers for Medicare and Medicaid Services estimates that 8,090 HHC agencies provide HHCS annually for more than 2.4 million elderly and disabled people. ${ }^{13}$ Furthermore, HHCS is provided by the state free of charge under the national health services in England. ${ }^{14}$ In the Kingdom of Saudi Arabia (KSA), an HHC program was established at King Faisal Specialized Hospital and Research Center in 1991 for patients with advanced cancer. ${ }^{15}$ In 2008, another HHC program was established by the Saudi Ministry of Health $(\mathrm{MOH})$; this program provides therapeutic, preventive, educational, rehabilitation, and social services by a qualified medical team. The MOH stated that HHCS provides the highest quality of care and continuous care to patients in their homes within the framework of Islamic values and traditions of the society. ${ }^{16}$ Although Arab countries have made remarkable strides in the area of patient safety in acute care settings, there is limited understanding about the health and safety hazards associated with home care, and these hazards can have far-reaching consequences on the health and well-being of home-care patients. Notably, an unsafe household can have adverse effects not only on the patient, but also on HHC providers and household caregivers.

Disclosure. Authors have no conflict of interests, and the work was not supported or funded by any drug company.
Moreover, considering that no systematic review has examined the quality of HHC in Arab countries and to address the research gap in HHC, we conducted this review to provide a comprehensive summary of the quality dimension of $\mathrm{HHC}$ and to assess the extent of the quality of $\mathrm{HHC}$ in Arab countries.

Methods. In 2017, we reviewed and identified relevant published studies via an online literature search using Embase, Cinhel, PubMed, and Cochrane library databases. The following keywords were used during the search: Quality OR Quality of care OR healthcare quality OR safe or effective OR Patientcentered OR timely OR efficient OR equitable AND Saudi Arabia OR Egypt OR Algeria OR Sudan OR Iraq OR Morocco OR Yemen OR Syria OR Tunisia OR Somalia OR Jordan OR United Arab Emirates OR Libya OR Palestine OR Lebanon OR Oman or Kuwait OR Mauritania OR Qatar OR Bahrain OR Djibouti OR Comoros AND Home Healthcare OR Home Care Services.

Only those studies that met the following criteria were included: focused on issues, problems, barriers, and challenges, particularly those describing the quality of HHC in Arab countries, related to the STEEP quality dimension, and published in English or Arabic language. However, studies concerning the quality of hospitals or primary healthcare were excluded from this review.

Primarily, we screened the articles according to titles. We also checked cross-references for the final articles. In the second screening round, 2 authors (MA and KA) evaluated the titles and the abstracts of the included articles. In the final screening step, 2 authors $(\mathrm{HH}$ and AA) independently reviewed and assessed the full texts of the included articles that met the inclusion criteria, and difference in opinion was resolved by consensus following a discussion between both reviewers. If both the authors stated that a study did not meet the inclusion criteria, it was excluded.

After the final selection of papers, the authors extracted the following details from the included full-text articles using a structured data collection sheet developed for this study which comprised of information regarding author, year of publication, country, study design, number of participants, participant type, and the main finding.

To evaluate the quality and risk of bias of the included studies, the Newcastle-Ottawa scale was used for casecontrol and cohort studies. The Newcastle-Ottawa scale assesses the quality of systematic reviews and 
meta-analyses. ${ }^{17}$ There are 8 items to assess the studies in this tool. Each item is assigned scores depending on 3 major domains: selection, comparability, and outcome. Under the selection, the representativeness of the exposed cohort, selection of the non-exposed cohort, and outcome not present at baseline and ascertainment of exposure were assessed. Comparability was based upon whether the design or analysis was controlled for confounders. The outcome was assessed as with either sufficient follow-up duration or adequate follow-up.

Ethical approval is not required for the systematic review.

Results. After our mutual consensus, 6 out of 214 studies met the inclusion criteria. Figure 1 shows the details of the study identification and selection processes.

When the Newcastle-Ottawa scale was used, we found our studies mostly scored from medium-to-low for bias (Tables $1 \& 2$ ). Out of 4 cohort studies, 2 studies scored 6 out of 8 on all domains, and the other 2 studies scored 7 out of 8 on all domains studied. This represents a good quality of evidence with medium-to-low bias. The only assessed case-control study scored 7 out of 8 for all studied domains, which again reflects upon the good quality index.

Most of the studies were conducted in KSA (4 articles), followed by Jordan (one article) and Iraq (one article). We grouped the findings under 3 main subheadings: safety and efficacy of HHCS, effectiveness, and efficiency of HHCS, and quality of life (QOL). Table 3 presents a complete list of the data extracted from the included studies.

Safety and efficacy of HHCS. Baharoon et al ${ }^{18}$ reported that home-based antibiotic treatment programs are being increasingly used worldwide. These programs have the advantage that it spans all age groups. For elderly patients, in particular, the incidence

Embase $(n=172)$ Cinhel $(n=18)$ Cochrane $(n=9)$ PubMed $(n=15)$

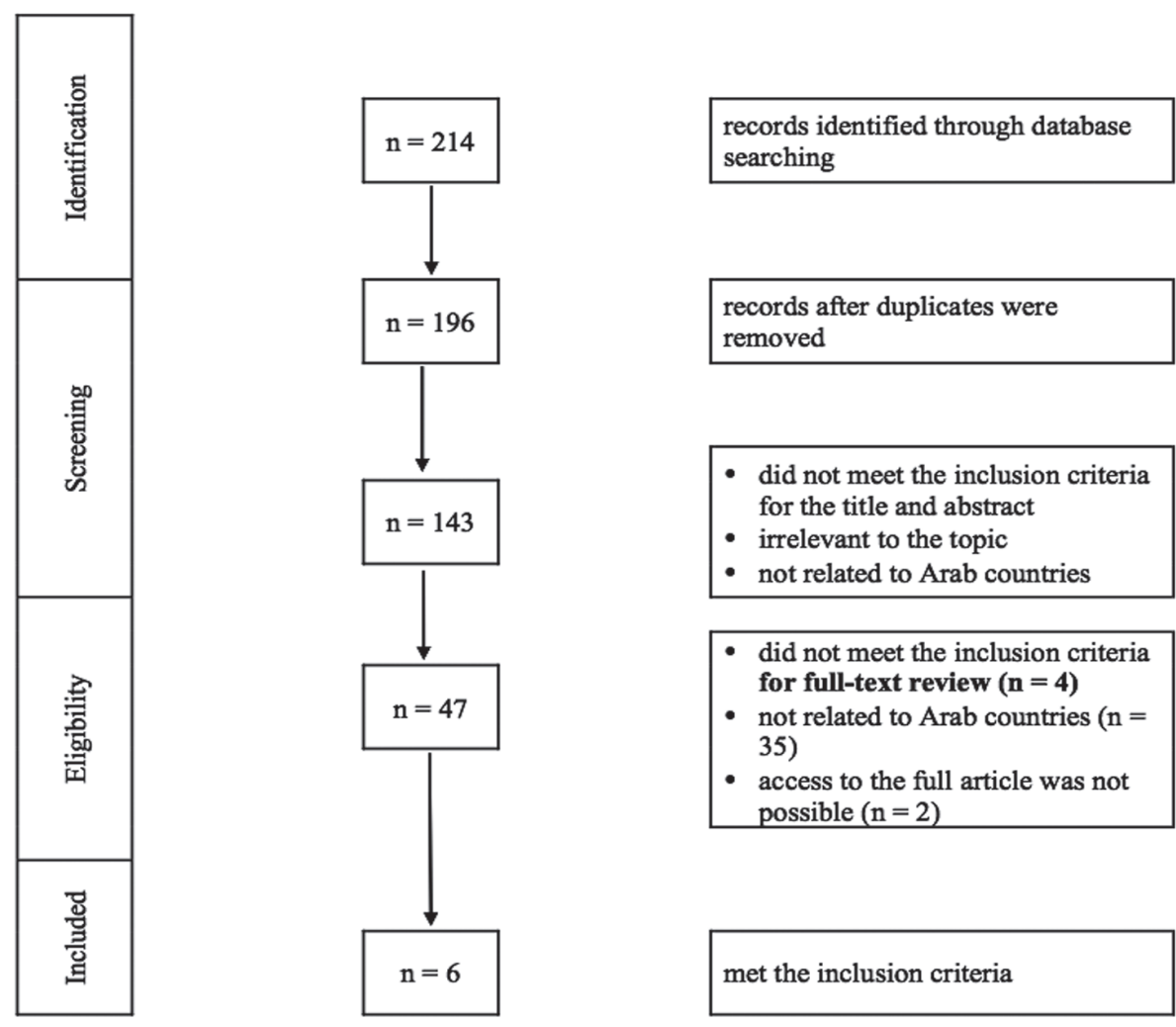

Figure 1 - Flow chart of the study selection process 
Table 1 - Newcastle-Ottawa scale for the cohort study.

\begin{tabular}{|c|c|c|c|c|c|c|c|c|c|}
\hline \multirow[t]{2}{*}{ Study ID } & \multicolumn{4}{|c|}{ Selection } & \multirow[t]{2}{*}{ Comparability } & \multicolumn{3}{|c|}{ Outcome } & \multirow{2}{*}{$\begin{array}{c}\text { Total } \\
\text { score } \\
\text { out of } 8\end{array}$} \\
\hline & $\begin{array}{c}\text { Representativeness } \\
\text { of the exposed } \\
\text { cohort }\end{array}$ & $\begin{array}{l}\text { Selection } \\
\text { of the non- } \\
\text { exposed } \\
\text { cohort }\end{array}$ & $\begin{array}{l}\text { Ascertainment } \\
\text { of exposure }\end{array}$ & $\begin{array}{c}\text { Outcome not } \\
\text { present at } \\
\text { baseline }\end{array}$ & & Assessment & $\begin{array}{c}\text { Sufficient } \\
\text { follow-up } \\
\text { duration }\end{array}$ & $\begin{array}{l}\text { Adequate } \\
\text { follow-up }\end{array}$ & \\
\hline Baharoon et $\mathrm{al}^{18}$ & $\sqrt{ }$ & & $\sqrt{ }$ & & $\sqrt{ }$ & $\sqrt{ }$ & $\sqrt{ }$ & $\sqrt{ }$ & 6 \\
\hline Al-Modeer et $\mathrm{al}^{22}$ & $\sqrt{ }$ & & $\sqrt{ }$ & & $\sqrt{ }$ & $\sqrt{ }$ & $\sqrt{ }$ & $\sqrt{ }$ & 6 \\
\hline Dhahi $^{20}$ & $\sqrt{ }$ & & $\sqrt{ }$ & & $\sqrt{ }$ & $\sqrt{ }$ & $\sqrt{ }$ & $\sqrt{ }$ & 7 \\
\hline Mutwalli et $\mathrm{a}^{23}$ & $\sqrt{ }$ & $\sqrt{ }$ & $\sqrt{ }$ & & $\sqrt{ }$ & $\sqrt{ }$ & $\sqrt{ }$ & $\sqrt{ }$ & 7 \\
\hline
\end{tabular}

Table 2 - Newcastle-Ottawa scale for the case-control study.

\begin{tabular}{|c|c|c|c|c|c|c|c|c|c|}
\hline \multirow[t]{2}{*}{ Study ID } & \multicolumn{4}{|c|}{ Selection } & \multirow[t]{2}{*}{ Comparability } & \multicolumn{3}{|c|}{ Exposure } & \multirow{2}{*}{$\begin{array}{c}\text { Total score } \\
\text { out of } 8\end{array}$} \\
\hline & $\begin{array}{l}\text { Is the case } \\
\text { definition } \\
\text { adequate? }\end{array}$ & $\begin{array}{c}\text { Representativeness } \\
\text { of the cases }\end{array}$ & $\begin{array}{l}\text { Selection } \\
\text { of controls }\end{array}$ & $\begin{array}{l}\text { Definition } \\
\text { of controls }\end{array}$ & & $\begin{array}{l}\text { Ascertain- } \\
\text { ment of } \\
\text { exposure }\end{array}$ & $\begin{array}{l}\text { The same method } \\
\text { of ascertainment } \\
\text { for cases and } \\
\text { controls }\end{array}$ & $\begin{array}{l}\text { Non } \\
\text { response } \\
\text { rate }\end{array}$ & \\
\hline Mohan, & $\sqrt{ }$ & $\sqrt{ }$ & $\sqrt{ }$ & $\sqrt{ }$ & & $\sqrt{ }$ & $\sqrt{ }$ & $\sqrt{ }$ & 7 \\
\hline
\end{tabular}

Table 3 - Summary of study characteristics included in the systematic review.

\begin{tabular}{|c|c|c|c|c|c|}
\hline Study & Country & Study design & $\begin{array}{l}\text { Number of } \\
\text { participants }\end{array}$ & Type of participants & Main finding \\
\hline $\begin{array}{l}\text { Baharoon et al }{ }^{18} \\
2011 \text { Sept - Oct }\end{array}$ & SA & Retrospective study & 155 & Patients & $\begin{array}{c}\text { Home IV antibiotic programs } \\
\text { should be used more frequently } \\
\text { as part of the healthcare system in } \\
\text { Saudi Arabia. }\end{array}$ \\
\hline $\begin{array}{l}\text { Al-Modeer et } \text { al }^{22} \\
\text { 2013 Jan - April }\end{array}$ & SA & Retrospective study & 880 & $\begin{array}{c}\text { Elderly patients ( } \geq 60 \\
\text { years) }\end{array}$ & $\begin{array}{l}\text { Adding preventive, curative, and } \\
\text { rehabilitative programs in HHCS is } \\
\text { greatly needed for the elderly. }\end{array}$ \\
\hline $\begin{array}{l}\text { Ajlouni et al }{ }^{19} \\
2015 \text { July }\end{array}$ & Jordan & $\begin{array}{c}\text { Descriptive } \\
\text { qualitative study }\end{array}$ & 46 & $\begin{array}{l}\text { All of the } 46 \text { home } \\
\text { healthcare agencies } \\
\text { in Jordan }\end{array}$ & $\begin{array}{l}\text { The most important challenges in } \\
\text { implementing HHCS in Jordan, } \\
\text { and ways to overcome these issues } \\
\text { are discussed. }\end{array}$ \\
\hline $\begin{array}{l}\text { Mutwalli et al }{ }^{23} \\
2012\end{array}$ & SA & Randomized study & 49 & Patients & $\begin{array}{l}\text { The home-based CR program } \\
\text { improves health-related QOL } \\
\text { and risks factor profiles of patients } \\
\text { following coronary artery bypass } \\
\text { graft to a greater extent than the } \\
\text { standard hospital care. }\end{array}$ \\
\hline Dhahi $^{20} 2010$ & SA & Cross-sectional study & 160 & $\begin{array}{l}\text { HHCS staff at } \\
\text { secondary and } \\
\text { tertiary care hospitals } \\
\text { in Riyadh, Jeddah, } \\
\text { Dammam, Medina, } \\
\text { and Tabuk }\end{array}$ & $\begin{array}{l}\text { Having incentives and stress } \\
\text { management workshops will } \\
\text { reduce stress and burnout among } \\
\text { HHCS staff. }\end{array}$ \\
\hline Mohan et $\mathrm{al}^{21} 2013$ & I & Randomized study & 480 & Patients & $\begin{array}{l}\text { Home visits were highly effective } \\
\text { in improving treatment return } \\
\text { of patients who were late for } \\
\text { treatment }\end{array}$ \\
\hline
\end{tabular}


of many adverse events as a result of conventional hospitalization, such as delirium and functional worsening, is considerably reduced. Furthermore, these programs provide more freedom for young patients because they can resume their healthy lifestyles. These programs are effective, considering that they have low dropout rates and low overall complication rates, and are increasingly providing a safe and cost-effective alternative to in-hospital management of similar cases. ${ }^{18}$

Effectiveness and efficiency of HHCS. A study conducted by Musa ${ }^{19}$ in Jordan showed that the performance of the HHC industry is affected by many challenges and problems, which negatively affect the effectiveness, efficiency, and quality of services delivered to the patients. These problems include the lack of professional guidelines regarding the practice of protocols and quality indicators, absence of control and monitoring by health authorities, scarcity of professional female nurses, absence of discharge planning and referral system, absence of national service fee schedule, absence of health insurance coverage, inadequate licensing and resource systems for caregivers and lack of training programs, paucity of written policies and procedures, absence of health information system including medical record-keeping, prevalence of some unethical practices, poor governance and management practices, and overemphasis and domination of profit-making aspect on the expense of quality improvement. ${ }^{19}$

Meanwhile, another study conducted by Dhahi found that stress management workshops and incentives decreased the tension and stress among the HHCS staff members. ${ }^{20}$ Mohan et $\mathrm{a}^{21}$ reported that home visiting of trained personnel not only drastically improves the compliance of patients who are delayed in attendance for treatment but also their treatment success rate.

Quality of life. Mohamed et $\mathrm{a}^{22}$ conducted a study on elderly patients receiving HHCS in the Armed Forces Hospital in the southern region of Saudi Arabia; they found that preventive, curative, and rehabilitative programs improve the QOL among the elderly in HHCS. Mutwalli et $\mathrm{al}^{23}$ while measuring the effectiveness of a home-based cardiac rehabilitation (CR) program on patients with post-coronary artery bypasses graft found that the home-based CR program improves the health-related QOL of patients.

Discussion. This review has focused on the problems, barriers, challenges, and quality of $\mathrm{HHC}$ and summarized the previous studies conducted in Arab countries. The included studies measured 3 dimensions of quality, namely, safety, effectiveness, and efficacy. A study conducted by Al-Modeer ${ }^{22}$ considered QOL as one of the quality dimensions. Thus, we added QOL in our review. A study conducted by Baharoon et $\mathrm{al}^{18}$ on patients enrolled in the King Abdulaziz Medical City HHC IV Antibiotic Program from May 1, 2005 to December 30, 2007, concluded that the HHC-based IV antibiotic program was a safe and effective alternative for in-patient management of patients with nonlife-threatening infections and was related with a low complication rate. ${ }^{18}$

Meanwhile, Mohamed et $\mathrm{al}^{22}$ conducted a retrospective study on the QOL measurement of all patients registered at the HHCS in the Armed Forces Hospital, Saudi Arabia; they found that to improve the QOL of the elderly patients, preventive, curative, and rehabilitation programs should be added to HHCS. ${ }^{22}$ Mutwalli et $\mathrm{al}^{23}$ conducted a randomized study at King Fahd Armed Forces Hospital in Jeddah, Saudi Arabia and measured the effectiveness of a home-based CR program on patients with post-coronary artery bypasses graft. They found that the home-based CR program improves patients' health-related QOL.

Moreover, Mohan et $\mathrm{al}^{21}$ measured the effectiveness of home visits in compliance with the directly observed therapy, short course (DOTS). The study was conducted in Bagdad on 480 new patients with smear-positive tuberculosis who had delayed drug collection on one occasion. They randomized the patients into 2 groups: intervention (home visited) and control (not visited) groups. They found that home visits were highly effective in improving treatment return of patients who were late for treatment. ${ }^{21}$

Furthermore, Ajlouni et $\mathrm{a}^{19}$ conducted a descriptive qualitative study to identify the common issues, problems, barriers, and challenges in implementing HHCS. The study revealed that many factors could yield a negative impact on the effectiveness, efficiency, and quality of services delivered to patients at home. These factors include the lack of professional guidelines regarding the practice of protocols and quality indicators, absence of control and monitoring by health authorities, scarcity of professional female nurses, absence of discharge planning and referral system from hospitals to HHCS and vice versa, absence of national service fee schedule, absence of health insurance coverage, inadequate licensing and resource systems for caregivers and lack of training programs, paucity of written policies and procedures, absence of health information system including medical record-keeping, prevalence of some unethical practices, poor governance and management practices, and overemphasis and domination of profit-making aspect on the expense of 
quality improvement. ${ }^{19}$ To solve these issues and improve the effectiveness, efficiency, and quality of services, we need to develop partnerships and affiliation among HHCS, adopt professional guidelines, practice protocols and quality indicators for HHCS, control, and monitor performance of HHCAs by $\mathrm{MOH}$. Also, we need to encourage health insurance schemes to include HHCS in their insurance package; HHCAs should develop written policies and procedures, health information systems, medical records systems, continuous training programs, proper management practices, and a national service fee schedule for HHCS. ${ }^{18}$ Dhahi $^{20}$ assessed the prevalence of burnout among HHC staff members in Saudi Arabia and found that having incentives and stress management workshops reduces stress and burnout among HHCS staff members.

The review highlights the need to improve the quality of HHC, specifically in areas of timely, equitable, and patient-centered care. This study highlights that a national level awareness campaign for advocating comprehensive HHC policy is required in Arab countries. It would be highly beneficial if the care is provided in a timely, equitable, and patientcentered care manner. An example in this context is the home-based post-partum care. A higher number of researches, especially focusing on epidemiological characteristics and barriers to effective HHC, are the need of the hour.

Study limitation. Our study is one of the first systematic reviews reporting the quality of $\mathrm{HHC}$ in Arab countries. The limitation of this study was that varied factors underlying HHC quality could not be compared as the number of studies that fulfilled the inclusion criteria was few and as the topic remains largely unexplored in the Middle-East. Furthermore, the quantitative data could have been presented systematically rather than narratively, which we intend to do in the future by including more variables and datasets.

In conclusion, this review has shown that the scientific literature provides limited information on the quality of $\mathrm{HHC}$ in Arab countries. We also noted gaps in the literature and the lack of information. Also, no information is available in most countries. All studies were assessed according to three indicators, namely, safety, efficiency, and effectiveness, out of the 6 IOM indicators. Timely, equitable, and patient-centered care was not specifically reported in any of the included studies. Overall, this review shows the need to further improve the quality of $\mathrm{HHC}$ in Arab countries.

\section{References}

1. Institute of Medicine Committee on Quality of Health Care in A. Crossing the Quality Chasm: A New Health System for the 21st Century. Washington (DC): National Academies Press (US) Copyright 2001 by the National Academy of Sciences; 2001.

2. What is home health care? 2006 [Available from: http://www. medicare.gov/HHCompare/Home.asp?dest=NAV|Home $\mid$ Abou t|WhatIs\#TabTop.

3. Jacob B, Ritz B, Gehring U, Koch A, Bischof W, Wichmann $\mathrm{HE}$, et al. Indoor exposure to molds and allergic sensitization. Environ Health Perspect 2002; 110: 647-653.

4. Leaderer BP, Belanger K, Triche E, et al. Dust mite, cockroach, cat, and dog allergen concentrations in homes of asthmatic children in the northeastern United States: Impact of socioeconomic factors and population density. Environ Health Perspect 2002; 110: 419-425.

5. Litonjua AA, Carey VJ, Burge HA, et al. Exposure to cockroach allergen in the home is associated with incident doctordiagnosed asthma and recurrent wheezing. J Allergy Clin Immunol 2001; 107: 41-47.

6. Matte TD, Jacobs DE. Housing and health: Current issues and implications for research and programs. J Urban Health 2000; 77: 7-25.

7. Saegart S, Klitzman S, Freudenberg N, et al. Healthy housing: A structured review of published evaluations of U.S. interventions to improve health by modifying housing in the United States 1990-2001. Am J Public Health 2003; 98: 1471-1477.

8. Meyer JD, Muntaner C. Injuries in home health care workers: An analysis of occupational morbidity from a State compensation database. Am J Ind M 1999; 35: 295-301.

9. Klitzman S, Caravanos J, Deitcher D, et al. Prevalence and predictors of residential health hazards: A Pilot Study. J Occup Environ Hyg 2005; 2: 293-301.

10. Hughes RG. Patient safety and quality. Agency for healthcare research and quality (US). Rockville (MD): Agency for Healthcare Research and Quality (US); 2008.

11. Shaughnessy PW, Hittle DF, Crisler KS, Powell MC, Richard AA, Kramer AM, et al. Improving patient outcomes of home health care: findings from two demonstration trials of outcomebased quality improvement. J Am Geriatr Soc 2002; 50: 1354-1364.

12. Homecare is the solution 2006 [Available from: http:// www.aahomecare.org/associations/3208/files/home\%20 healthcare $\% 202 \% 20$ pager.pdf.

13. Home health quality initiative overview. 2006 [Available from: http://www.cms.hhs.gov/HomeHealthQualityInits.

14. Klein R. The new politics of the NHS: from creation to reinvention. Abingdon (UK) Radcliffe Publishing; 2010.

15. Gray A, Ezzat A. Palliative care for patients with advanced cancer. J Family Community Med 1997; 4: 41-46.

16. Ministry of Health. Home medical care need mean and principles. Saudi Arabia: Ministry of Health; 2011.

17. Deeks JJ, Dinnes J, D’Amico R, Sowden AJ, Sakarovitch C, Song F, et al. "Evaluating non-randomised intervention studies" (PDF). Health Technol Assess 2003; 7: 27.

18. Baharoon S, Almodaimeg $\mathrm{H}$, Al Watban $\mathrm{H}$, Al Jahdali $\mathrm{H}$, Alenazi T, Al Sayyari A, et al. Home intravenous antibiotics in a tertiary care hospital in Saudi Arabia. Ann Saudi Med 2011; 31: 457-461. 
19. Ajlouni MT, Dawani H, Diab SM. Home Health Care (HHC) Managers Perceptions About Challenges and Obstacles that Hinder HHC Services in Jordan. Glob J Health Sci 2015; 7: 121-129.

20. Dhahi SA. Prevalence of burnout among home health care staff members in Saudi Arabia, 2010. Eur Geriatr Med 2012; S66.

21. Mohan A, Nassir H, Niazi A. Does routine home visiting improve the return rate and outcome of DOTS patients who delay treatment? East Mediterr Health J 2003; 9: 702-708.
22. Al-Modeer MA, Hassanien NS, Jabloun CM. Profile of morbidity among elderly at home health care service in Southern Saudi Arabia. J Family Community Med 2013; 20: 53-57.

23. Mutwalli HA, Fallows SJ, Arnous AA, Zamzami MS. Randomized controlled evaluation shows the effectiveness of a home-based CR program. Saudi Med J 2012; 33; 152-159. 